Setting up new medical services

\title{
Adults with spina bifida and/or hydrocephalus
}

\author{
DJR Morgan, Maddie Blackburn, Martin Bax
}

\section{Summary}

Recent advances in medical technology enable many children with complex disabilities to survive into adulthood and to have certain expectations of life. One of these expectations is the continuity of specialist health care in an adult setting. This paper describes a new out-patient service which aims to provide optimum care, continuity and consistency of service for adults with spina bifida and/or hydrocephalus. The need for specialist health input into this service, in order to monitor the neurological, urological and psychosocial complications often associated with spina bifida and/or hydrocephalus is recognised. In one year (1992), 86 young adults with spina bifida and/or hydrocephalus attended for annual or more frequent assessment, either independently or with their families or carers. A variety of health and social problems were treated. In response to demand, a multidisciplinary assessment unit, which includes the services of both medical and nursing specialists, occupational and physiotherapists, psychologists and access to specialist surgical opinions has recently opened at the Chelsea and Westminster Hospital. This new service attempts to meet some of the needs described in the outpatient audit. Adults with other disabilities are requesting to use this service. A longitudinal study to monitor quality, and outcome is indicated from this initial survey.

Chelsea and Westminster Hospital, London SW10, UK

DJR Morgan

M Blackburn

M Bax

Correspondence to Dr DJR Morgan, Academic Department of Therapeutics, Chelsea and Westminster Hospital, 369 Fulham Road, London SW10 9NH, UK

Accepted 4 October 1994

\section{Introduction}

The outcome for young adults with disabilities is bleak, particularly in relation to health care, education and career provision. A particular decline in contact with the Health and Social Service departments after the age of 16 years has been reported. ${ }^{1}$ Recent advances in medical technology mean that many children with complex disabilities now survive into adulthood and have certain expectations of life. ${ }^{2}$ Some of these include the continuity of health care beyond childhood. Because intensive treatment of spina bifida and/or hydrocephalus really began in the early 1960 s, it is only recently that relatively large numbers of people with this condition have survived into adulthood and required the continuation of medical services. Survival and incidence rates of spina bifida and/or hydrocephalus are changing significantly. Prevalence in young adulthood was formerly estimated at two per 100000 school leavers, ${ }^{3}$ but it would seem that this figure is now declining. ${ }^{4}$ Advanced surgical techniques in the 1960 s resulted in a large number of survivors with severe complex needs. ${ }^{5}$ As yet there are few established adult specialist clinics around the UK. Those clinics which have developed are often present because of the enthusiasm and specialist interest of particular clinicians. ${ }^{6}$

\section{Methods}

This study was approved by the local research ethics committee. All patients consented to their participation. Initially, patients were referred to the adult outpatient clinic from the (former) Westminster Children's Hospital. The adult physician attended a joint clinic with his paediatric surgical colleagues. Introductions were made and both patients and their carers given information about the adult clinic (see box). An explanatory leaflet outlining the aims and objectives of the adult service and emergency contact numbers were given to the young person/carer at the 'handover' clinic. The physician has established referral routes to specific colleagues for expert advice, both within and outside the hospital. These include an orthopaedic surgeon, neurosurgeon and urologist. Now the adult service is established, referrals from other sources are being received.

At the first visit, all young adults received a comprehensive medical examination and social review. Where possible and based on prior information received from the paediatric clinic, routine investigations were performed at this time. These included X-rays and neurological and urological function tests which included ultrasound and kidney scans. The adults were sometimes admitted to hospital so that necessary procedures could be undertaken and lengthy, repeated visits to the hospital thus avoided.

Routinely, most patients saw the research health visitor and the continence advisor. The continence advisor advised on problems associated with bowel and/or urinary continence while the health visitor dealt with more general health issues and her specialist area of sexuality and disability. Both were prepared to discuss social and psychosocial matters with patients and families. Where necessary, referrals were made to the 'Association for Spina Bifida and Hydrocephalus' (ASBAH), with the patient's prior permission.

\section{Results}

During the twelve-month audit, 86 young people were seen (see box) of whom 37 were male, and 49 female, with a mean age of 21.3 years. Ten adults attended independently of carers. Only four failed to keep initial appointments and all of these phoned for another which they attended (table 1). All patients were offered an annual review but were advised they could attend earlier if required, or in an emergency. Initial medical assessments usually lasted about one hour. 


\begin{tabular}{|l|}
\hline Clinic staff \\
\hline - Consultant physician \\
- Continence adviser \\
- Health visitor \\
\hline
\end{tabular}

\begin{tabular}{|lr|}
\hline Pilot patient sample \\
\hline Spina bifida and/or & 48 \\
hydrocephalus & \\
Spina bifida only & 32 \\
Hydrocephalus only & 6 \\
Total & 86 \\
\hline
\end{tabular}

\begin{tabular}{|l|}
\hline Spina bifida/hydrocephalus: \\
problems \\
\hline - chest deformity \\
- renal failure \\
- skeletal pain \\
- headache, epilepsy \\
- incontinence \\
- pressure sores \\
behavioural and/or social \\
\hline
\end{tabular}

Table 1 Number of out-patient attendances (1992)

\begin{tabular}{ll}
\hline Number of visits & Number of patients \\
\hline 1 & 86 \\
2 & 21 \\
3 & 7 \\
4 & 6 \\
$\geqslant 5$ & 6 \\
none & 4 \\
\hline
\end{tabular}

Table 2 Number of hospital admissions of clinic patients

\begin{tabular}{ll}
\hline Admissions & Number \\
\hline Ventricular atrial shunt revision & 2 \\
Pressure ulcer care & 2 \\
Cystoscopy for renal stone & 1 \\
Specific bowel management & 1 \\
Urological assessment and social & 1 \\
provision & 1 \\
Deaths during 1992 & \\
\hline
\end{tabular}

ADMISSION TO HOSPITAL

All patients were first assessed by the physician. Some patients were offered hospital admission for a more detailed assessment and possible referral to the adult urologist, neurosurgeon and/or orthopaedic surgeon. Seven young adults were admitted to hospital for investigations, following out-patient attendance (table 2). These admissions were also used to perform urological assessments which were due. All patients were admitted to a specialist unit, irrespective of reason for admission.

\section{PROBLEMS ENCOUNTERED}

A variety of medical conditions were present, both related and unrelated to their disabilities. Many patients had complications associated with spina bifida and/or hydrocephalus which required careful monitoring and assessment (see box).

\section{Problems assessed by the physician}

\section{SHUNT DIFFICULTIES}

The majority of patients with hydrocephalus required examination or assessment of their shunt. Fourteen patients reported a variety of symptoms including headaches, nausea, blackouts and general malaise which the young person or carer often attributed to shunt malfunction; two patients had migraine.

\section{CONTINENCE}

Continence problems were reported by 56 patients, 23 of whom reported current bowel or urinary continence difficulties. Eighteen patients had 'neurogenic bladder', four had urinary diversions and one had a Mitrofanoff operation. Five who were performing clean intermittent catheterisation sought further assistance and information about this procedure. Several adults and their families wished to discuss new surgical techniques. Several patients awaiting urodynamic assessment began clean intermittent catheterisation following consultation with the physician and instruction with the continence advisor. Some patients requested dietary advice or medication for their bowels.

\section{MOBILITY}

Fifty patients regularly used a wheelchair. Six patients required specific wheelchair maintenance: tyres, seating, back supports, foot and side plates required modification. All of these patients were subsequently referred to a mobility service for appropriate wheelchair assessment.

\section{SKIN PROBLEMS}

Five patients reported pressure sores on their spine, buttocks, ankles and feet Two required hospital admission for surgical debridement. Two were referred to appropriate wheelchair agencies because of associated skin problems. Al patients were offered skin care advice and treatment.

\section{BEHAVIOURAL DIFFICULTIES}

Six people presented with particular behaviour problems. Some parents reported that their son or daughter frequently displayed difficult behaviour. Such behaviour included eating carpet, biting, self-mutilation, head banging, and screaming repetitively. Although possible causes were discussed with the physician and health advisers, follow-up domiciliary assessments were usually arranged with the ASBAH hydrocephalus support worker. Several young people reported depression. One man reported two recent suicide attempts as a result of psychosocial problems. Many young adults had seen a psychologist during childhood and were noted to have moderate to severe learning difficulties. Without a psychologist initially, we were unable to re-assess their present cognitive function.

OTHER ISSUES

Seventeen patients had active epilepsy, requiring surveillance and occasional modification to previously prescribed medication. One patient had myxoedema.

ISSUES DISCUSSED WITH THE HEALTH ADVISERS

The health visitor and/or continence advisor discussed continence, disability, psychosocial or other health issues. Ten patients requested information about independence training programmes and housing and four had specific financial concerns. Many were referred to the ASBAH or other agencies for additional help. Several patients wished to discuss sexuality, family planning and genetic risks. Three patients contemplating marriage required more specific information. Family planning advice and information about genetic risks were given to 
Table 3 Patient satisfaction with new all-day adult disability service (1993-4)

\begin{tabular}{ll}
\hline Comments & Number \\
\hline Think service is useful & 58 \\
Think service should be & 13 \\
provided locally & \\
Happy to travel to the hospital & 57 \\
Service could be improved & 10
\end{tabular}

Total $=60$ written evaluations (from a possible total of 80 ).

\section{Adults with hydrocephalus spina bifida}

Considerations

- independence

- abuse

- sex education

- continence management six patients. One woman with myelomeningocele and one with hydrocephalus had their first babies during the study period. Two women disclosed that they had been raped and were referred, with their approval, to appropriate agencies for counselling support. Two men retrospectively disclosed that they had been physically abused and others reported 'bullying', These young adults were subsequently relocated to other day centres and additional help was sought from other agencies. Two mothers requested child care advice and were subsequently referred to the community health visitor. The disclosures of rape and abuse were discussed with both the physician and health visitor. Patients agreed to agency intervention and accepted referral to specialist counsellors. Both the young adults and their relatives understandably wished to discuss personal issues independently of each other. Parents often requested assistance with some of the behaviour difficulties frequently associated with hydrocephalus. ${ }^{7}$ Those patients were referred for specialist follow up. The continence advisor subsequently visited patients at home to advise about clean intermittent catheterisation and other continence procedures. Over half the young people had unmet medical needs when seen and were grateful for the offer of at least an annual assessment. It is noteworthy that every patient offered an appointment attended this clinic despite the distance they had to travel and transport difficulties. All patients wished this service to be continued (table 3 ).

\section{Discussion}

It is a misconception to believe that paediatric management of congenital abnormality is complete and that adult services will be unnecessary after the age of 16 years. Some young people may have difficulties in accomplishing taks without specialist help in adulthood. Therefore the young person not only requires a physician and multi-disciplinary team in hospital but also a range of rehabilitation services within the community. Some might argue that the disabled child should at least be in a stable condition by the time he or she reaches adulthood, therefore rendering regular surveillance unnecessary. Our experiences suggest the contrary. People with disabilities continue to have health needs which need appropriate supervision and active intervention throughout adult life and not just childhood. ${ }^{10}$ New problems develop. For example, many adults need advice from specialists about genetic risks, sexuality, fertility and independence.

Our experience from this initial evaluation has highlighted the limitations of the conventional out-patient setting. Whether such services should be provided at district or regional level, or within hospital or the community is a subject of current debate. Recent reforms within the National Health Service (NHS) have effected the position of district and regional health services. This is further compounded by the health authority or trust status of the hospital and the identified purchasers and providers of service. General practitioners may be forced to refer patients to a local out-patient service regardless of whether specialist expertise is available. Previously many general practitioners referred patients with complex disabilities to a specialist regional centre. The NHS and Community Care Act 1990 had shifted the emphasis of caring for disabled people to the community rather than in hospital. Arguably this service should be provided by community multi-disciplinary rehabilitation specialists in collaboration with general practitioners. However, our present convenience of hospital multidisciplinary consultation in addition to simultaneous 'on-site' investigations may be preferable to the current dearth of adult community rehabilitation centres. Clearly it is important for the hospital specialists to work collaboratively with general practitioners, other members of the primary health care team, staff from the voluntary sector, and those rehabilitation specialists who may currently be providing services. ${ }^{5}$

\section{INDEPENDENCE}

The 10 adults who requested information about independence training were all living at home with parents. A third of the sample had attended independence training programmes provided by ASBAH, the Queen Elizabeth foundation, Lord Mayor Treloar and the Chailey Heritage Centres. Clearly the young person not only requires a specialist team in hospital, but also access to a range of community specialists who may assist with independence programmes.

\section{ABUSE}

Several adults had experienced either physical or sexual abuse during childhood and adolescence. Staff require the necessary knowledge, skills and ability to listen, believe and respond accordingly to such disclosures. Recent research suggests that disabled children and adults are at increased risk of abuse. ${ }^{8}$ Many 
disabled adults are reticent and frequently delay disclosing abuse. In a recent study, $10 \%$ of adults with spina bifida and/or hydrocephalus disclosed abuse. ${ }^{9}$ Those who previously argued that disabled children and adults cannot be abused are now being challenged. ${ }^{10}$

\section{SEX EDUCATION}

Sex education is important throughout childhood for both able-bodied and disabled people. ${ }^{9}$ Information about sex should be available for disabled people throughout adult life, as there are often unresolved questions which recur and others which may subsequently arise. Advice may be needed on relationships and 'love-making', contraception, continence and sexuality. Genetic information may also be required. Sex education programmes should include awareness of abuse. Ideally, audio-visual information about sexual matters should be available within the clinic.

\section{CONTINENCE MANAGEMENT}

Although many of these adults received advice from continence specialists throughout childhood, new techniques and improvement to more traditional methods of continence management warrant continued advice from specialist physicians, urologists and continence advisors. The trial and failure of one technique in the past should not preclude further experimentation in later life.

\section{Service provision}

There was a limited spread of specialists in our conventional, weekly outpatient clinic. Clearly a team which included both medical and para-medical specialists and who had a commitment and understanding of the diverse needs of this population was needed. An adult assessment service has recently (1993) been established within the Chelsea and Westminster Hospital (table 4). This service is led and coordinated by a consultant physician with a specialist interest and knowledge of spina bifida and/or hydrocephalus. Such a physician cannot work in isolation without paramedical specialist back-up both within the hospital and in the community. In addition the physician must be aware of the psychosocial as well as the medical needs of the young person during the important transition period from childhood to adulthood where clearly the aim is for the young person to become more socially independent, acquire more practical skills and hopefully interact with his/her peers. Our new service also includes associated support from consultant urologists, orthopaedic surgeons, neurosurgeons and geneticists for technical advice and management of specific problems. Paramedical specialists include clinical nurse specialists, continence advisers, disabled living advisers, psychologists, and occupational and physiotherapists (table 4). At the same time the staff try to provide a relaxed and informal atmosphere for young people and their carers. To achieve this, careful planning and coordination is required. This frequently depends upon the diplomatic organisation skills of various members of the team and, not least, the physician's secretary.

\section{OTHER FACTORS}

Although many patients currently using the service are over 21 years, the majority are still accompanied by parents/carers. Many young adults still live at home and are cared for by parents but often need encouragement to become more socially independent. ${ }^{14} \mathrm{~A}$ few adults are employed, living independently and are closely supported by ASBAH community fieldworkers who regularly liaise with our team. Both young adults and their carers are encouraged to request

Table 4 Aims of the assessment unit

1. A full day appointment to see various specialists, thus avoiding the customary additional visits previously required (some families travel long distances; mean average distance $=35$ miles).

2. Good liaison with departments, so that planned investigation for urodynamic and neurological investigations such as CT scans, electroencephalograms, X-rays, ultrasound scans, imaging isotopes and urodynamics can be booked to coincide with the assessment.

3. Technical and appliance advice for young adults using wheelchairs, callipers and orthopaedic braces.

4. Availability of equipment, medications and appliances to coincide with visits, eg pharmacy, continence and contraceptive supplies.

5. Reliable patient transport, easy parking, accessible facilities

6. Psycho-social support and a commitment to initiating or developing independence programmes within the community. 
individual consultations with specialists. Some young people need to be encouraged to handle their own health and personal needs, although this may not be possible if they have severe learning disabilities. ${ }^{13}$ Aging parents often require practical and social support in order to continue caring for their 'adult children', but also to make provision for their own as well as their son's/daughter's future. Most of the families seem happy to travel, in spite of distance, to attend the all-day service for comprehensive review (see table 3 ).

\section{Conclusion}

It is now recognised that it is inappropriate to provide care for young adults over the age of 16 years in a paediatric setting. ${ }^{2}$ Our evidence suggests that certain functional problems persist and that new health needs and changing psychosocial demands necessitate a continuing service provided by specialists who are able to assist and advise young adults and their families in safeguarding and achieving optimum health. This report has only addressed some of the specific issues related to spina bifida and/or hydrocephalus. Other young disabled people require a similar service. ${ }^{11,12}$ An increasing number of requests have been received to accommodate other disabled adults within our facilities. This initial review suggests further development of this specialised service with prospective, longitudinal evaluation incorporating the functional independence measure scales. ${ }^{15}$ This assessment scale may help provide additional information on key functional and social attributes of the young disabled person. Ideally this service should be provided either within the community or at district level. Equally we recognise that the professional expertise necessary for such provision may not be available at a district level and a regional, hospital-based service, as described, may still be necessary and perhaps more cost effective.

The authors would like to acknowledge the assistance of $\mathrm{Mr}$ Duncan Forest, former Consultant Surgeon, Westminster Children's Hospital, London; Mr Jeremy Lawson, former Consultant Surgeon, Westminster Children's and St Thomas' Hospital, London; Mr Nicholas Madden, Consultant Paediatric Surgeon, Chelsea and Westminster Hospital, London, and Ms Jane Williams, Disabled Living Adviser, ASBAH.

1 Thomas AP, Bax MCO, Smyth DPL. The health and social needs of young adults with physical disabilities. Oxford: Mac Keith Press, Blackwells Scientific Publications, 1989.

2 Blum RW, Resnick MD, Nelson R, St Germaine A. Family and peer issues among adolescents with spina bifida and cerebral palsy. Paediatrics. 88: $280-5$.

3 Castree BJ, Walker JH. The young adult with Castree BJ, Walker JH. The young ad
spina bifida. $B M F$ 1981; 283: 1040-2.

4 Lawton D. Incidence of spina bifida on Family Lawton D. Incidence of spina bifida on Family
Fund Register: year of birth 1957-1991. York: Family Fund, 1992.

5 Chamberlain MA, Guthrie S, Kettle M, Stowe J. An assessment of health and related needs of physically handicapped young adults. London DOH, 1993.

6 Beardshaw $\mathrm{V}$. Last on the list : community services for people with physical disabilities. London: Kings Fund Institute, 1991

7 Tew B. The effects of spina bifida upon learning and behaviour. In: Bannister CM, Tew B, eds. and behaviour. In: Bannister CM, Tew B, eds. cephalus. Oxford: Mac Keith Press, Blackwell cephalus. Oxford: Mac Keith Press,
Scientific Publications, 1991; p 169.

8 Westcott H. Abuse of children with disabilities.

Westcott H. Abuse of children with disabilities. NSPCC
9 Blackburn MC, Bax MCO. Sex education provision for young adults with spina bifida and hydrocephalus: evaluation of a pilot training video. Eur $\mathcal{F}$ Paediatr Surg 1992; 2 (suppl 1): 39-40.

10 Marchant R. Myths and facts about sexual abuse and children with disabilities. Child Abuse Rev 1991; 5(2): 22-4

11 Parker G, Hirst $M$. Continuity and change in 1 Parker G, Hirst $M$. Continuity and change in medical care for young adults with disa

12 Robson BJ. Report on the Newcastle young adult clinic for the disabled. Newcastle upon Tyne. Department of Orthopaedics, Freeman Hospital, 1982.

13 Hurst MA, Baldwin SM. Unequal opportunities: growing up disabled. HMSO 1994 ISBN 0117018287.

14 Blackburn MC. Parents perceptions and needs in supporting the young adult with spina bidfida and/or hydrocephalus. Link (Journal for people with spina bifida and/or hydrocephalus) 1994; Oct/Nov.

$15 \mathrm{Keith} \mathrm{RA}$. The functional assessment measures in medical rehabilitation: current staus. Arch Phys Med Rehabil 1984; 65: 341-5. 